\title{
Tidal bending and strand cracks at the Kamb Ice Stream grounding line, West Antarctica
}

\author{
CHRISTINA L. HULBE, ${ }^{1 *}$ MARIN KLINGER, ${ }^{2}$ MEGAN MASTERSON, ${ }^{1}$ \\ GINNY CATANIA, ${ }^{3}$ KENNETH CRUIKSHANK, ${ }^{1}$ ANDREA BUGNI ${ }^{4}$ \\ ${ }^{1}$ Department of Geology, Portland State University, PO Box 751, Portland, OR 97201, USA \\ ${ }^{2}$ National Snow and Ice Data Center, Boulder, CO, USA \\ ${ }^{3}$ Institute for Geophysics, University of Texas at Austin, Austin, TX, USA \\ ${ }^{4}$ Estacada, OR, USA \\ Correspondence: Christina L. Hulbe <christina.hulbe@otago.ac.nz>
}

\begin{abstract}
An extensive set of shore-parallel fractures are observed at the grounding line of Kamb Ice Stream (KIS) in West Antarctica. Seismicity measured in the grounding zone is, as elsewhere around Antarctica, tidally forced and moreover strand cracks propagate nearly exclusively on the falling tide. Measured surface deflection and a model of fracture propagation are used to conclude that bending on the falling tide favors propagation while bending on the rising tide suppresses propagation. Without the perturbation due to tidal bending, strand cracks would be rare and appear farther downstream than observed. We speculate that the very large number of cracks observed at KIS is due to the stagnant-to-floating transition at that grounding line, which allows cyclic bending of the same ice and relatively large stretching rates.
\end{abstract}

KEYWORDS: grounding line, ice fracture propagation, ice shelves

\section{INTRODUCTION}

The earliest scientific explorers of Antarctica mapped slope breaks and strand cracks near the coastline and connected the features with ice ungrounding into floating shelves (cf. Swithinbank, 1955; Robin, 1958). Since those early investigations, grounding zones (transitions from fully grounded to fully floating ice) have been recognized as critical boundaries in understanding change in the ice-sheet/ice-shelf system (Mercer, 1978; Thomas and others, 1979; Schoof and Hewitt, 2013). This transition is where water stored in the ice sheet returns to the sea and its location is related to the overall mass balance of the system. Migration of the grounding line is also associated with an instability in marine ice-sheet systems, whereby an initial perturbation due to climate yields a dynamically-driven response in the ice sheet (Schoof, 2007).

The coastline of the Ross Sea sector of the West Antarctic Ice Sheet (Ross-WAIS) is characterized by several grounding zone morphologies. Because basal traction is smaller on the floating side than on the grounded side of the transition, the surface on the floating side must be smooth and low slope. Basal traction on the grounded side can support a steeper slope, particularly where the interface between the ice and substrate is frozen. In all cases, the transition from grounded to floating will be marked by locally steep surface slope, but the difference will be more subtle where transition in basal traction is smaller, for example, from an ice stream into the ice shelf (e.g. Hindmarsh, 1993).

The boundary between grounded ice sheet and floating ice shelf is also a transition across which tidal displacement of the floating ice shelf is damped (cf. Vaughan, 1995; Brunt and others, 2010). Where it has been examined, tidal

* Present address: National School of Surveying, University of Otago, Dunedin, New Zealand. effects are observed many kilometers inland of the grounding line on fast-flowing streams (cf. Anandakrishnan and Alley, 1997; Anandakrishnan and others, 2003; Bindschadler and others, 2003; Winberry and others, 2011). Here we are concerned with vertical displacement of ice near the grounding zone of and its role in the development of surface fractures (often called strand cracks) at that boundary.

Kamb Ice Stream (KIS) is one of the five major ice streams flowing from the interior of the WAIS into the Ross Ice Shelf (RIS). KIS stagnated in its downstream reach $\sim 160$ a BP (Retzlaff and Bentley, 1993) and today its grounding zone is characterized by a steep slope, relative to the other, fastflowing ice stream outlets. The difference is apparent in shadows cast along the grounding zone (Fig. 1) and, of course, in measurements of the surface elevation.

We observed and mapped numerous long, narrow strand cracks within a km-wide band along the KIS grounding zone slope in austral spring of 2006 and 2007 (Figs 1, 2). The cracks extend for many kilometers along the contour of the slope, with minor adjustments in horizontal propagation direction associated with near-field stress variations (cf. Cruikshank and Aydin, 1994). Crack widths at the surface range from a few $\mathrm{mm}$ to $\sim 5 \mathrm{~cm}$. The ultimate depths of the cracks are unknown but digging around one relatively large crack in 2007 showed it to extend at least $2 \mathrm{~m}$ below the snow surface.

The strand cracks at KIS appear to be particularly active. We heard numerous low-frequency popping sounds while working in the strand crack zone in November of 2006 and 2007. When we dug down into the snow around a crack we heard flurries of closely timed pops separated by several minutes or more. On some occasions, loud sounds were accompanied by minor firn settling. The sounds were common at some times of the day and absent at others, which we inferred to be associated with the tide. These qualitative observations are very similar to those made by Robin 


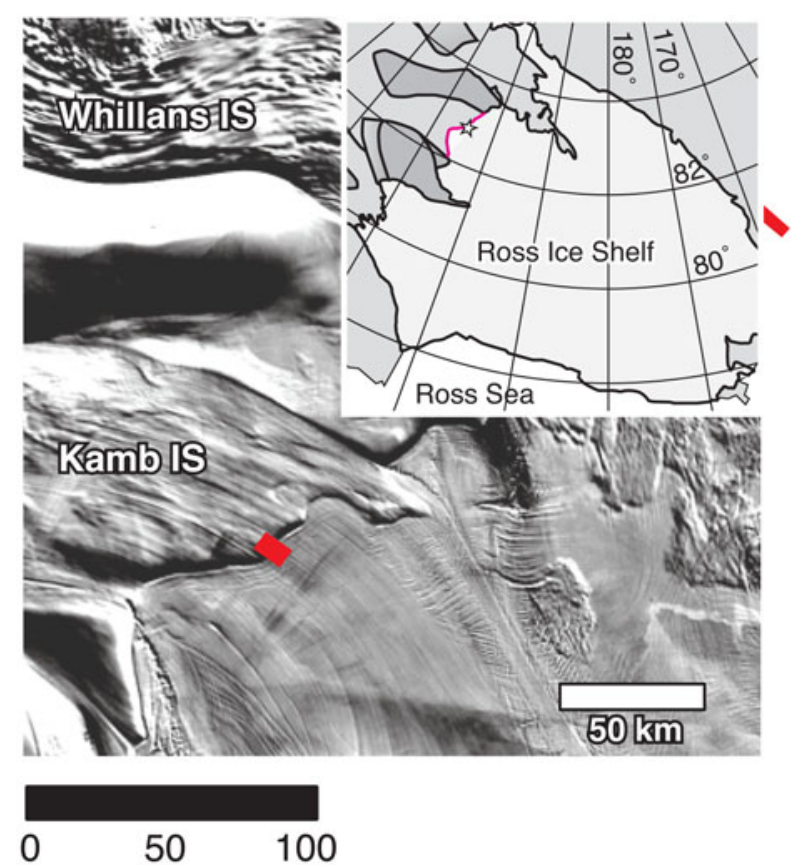

Fig. 1. Extract from the MODIS MOA (Haran and others, 2005), showing the outlet of KIS. Ice flow is approximately from the upper left toward the lower right. The red box shows the location of the strain grid. The inset shows the ice streams flowing into the ice shelf, the pink line traces the KIS grounding line and the star shows the location of the study.

(1958). In contrast to the situation at KIS, we observed few strand cracks on the north and south sides of the Whillans Ice Stream (WIS) grounding line when working there during the same field seasons, and never heard propagation events in the WIS grounding zone.

Our qualitative observations at the KIS grounding zone in 2006 led us to listen more quantitatively in 2007, using single-component, broadband geophones deployed at three locations in the strand cracks. We use the resulting seismicity record, together with vertical motion from continuous GPS observations, and strain rates from a survey grid across the grounding line to investigate why strand cracks are so abundant at KIS and why their propagation is periodic.

\section{OBSERVATIONS}

\subsection{Maps}

Strand cracks are observed exclusively on the downstream part of the KIS grounding zone slope, within an $\sim 1 \mathrm{~km}$ wide band that follows the contour of the slope. The surface traces of many cracks were mapped by driving along the features using real-time kinematic GPS (Fig. 3). Visible traces were mapped in detail in a $2 \mathrm{~km}$ wide section of the slope and their upstream and downstream limits were mapped over a longer segment of the slope. The along-flow spacing of major crack traces varies, but is in general $50 \mathrm{~m}$ or less.

The surface slope along the KIS grounding zone is about an order of magnitude larger than typical slopes along the nearby WIS grounding zone $\left(10 \mathrm{~m} \mathrm{~km}^{-1}\right.$ compared with $1 \mathrm{~m} \mathrm{~km}^{-1}$, Fretwell and others, 2013). A series of surface undulations on the floating side of the transition are observed near the center of the grounding zone (Figs 3, 4). Low

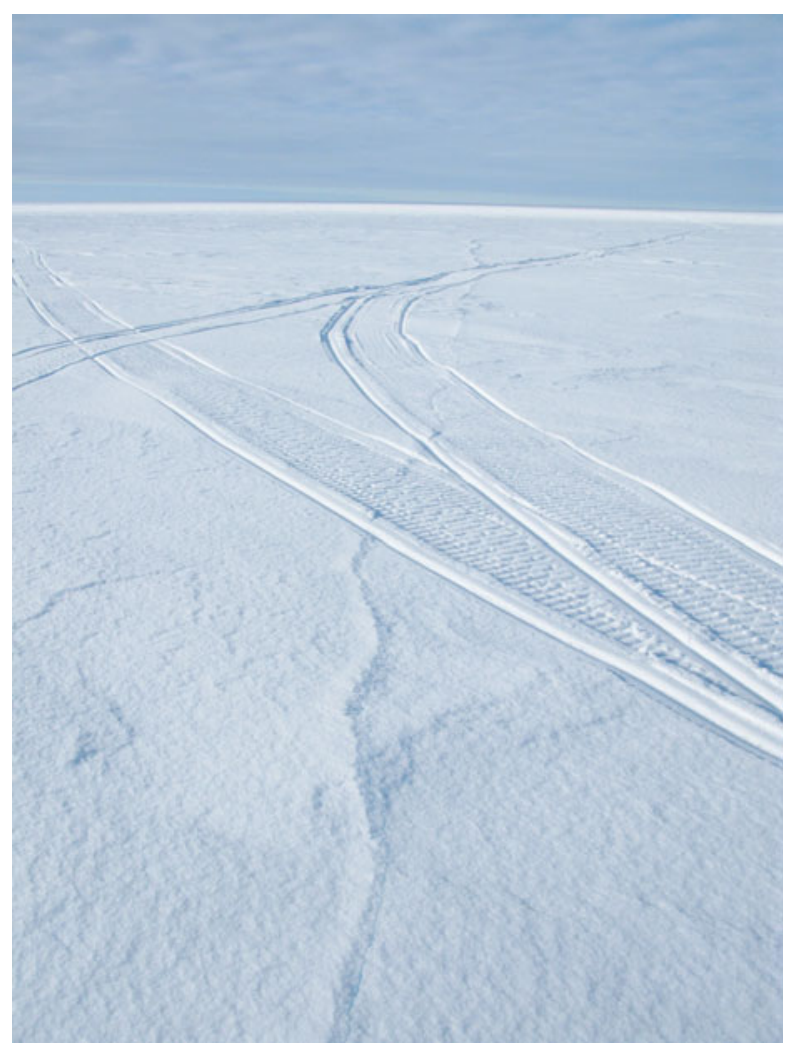

Fig. 2. Surface expression of a strand crack in the strain grid, near e2 as shown in Figure 3. Snowmobile tracks crossing the fracture are $\sim 0.38 \mathrm{~m}$ wide.

frequency radar imaging across the long wavelength, shallow undulations shows that the surface lows are not simply matched by basal crevasses (Hulbe and Catania, 2010; MacGregor and others, 2011). The origin of the

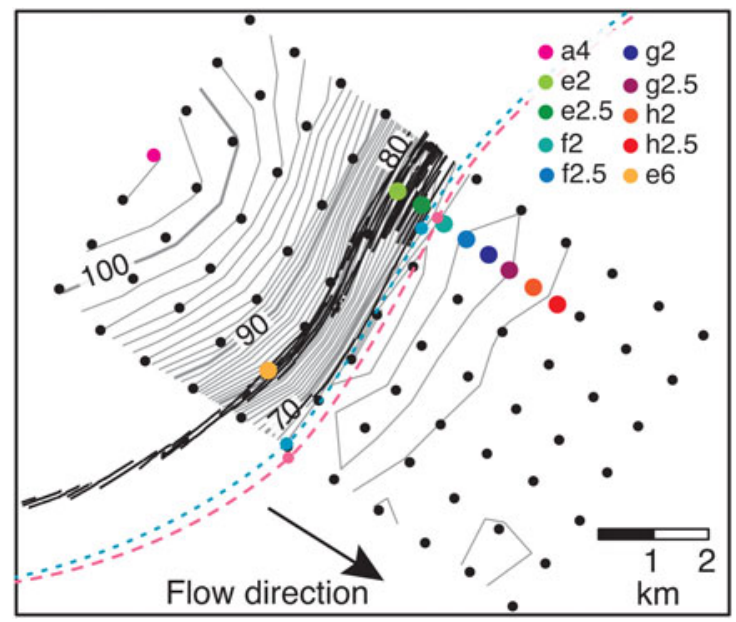

Fig. 3. Strain grid and continuous GPS stations together with surface relief measured in the study area. The contours are surface elevation in $1 \mathrm{~m}$ intervals, from GPS surveys of the grid. The heavy black lines represent mapped traces of strand cracks observed at the ice surface (only some features are mapped, as described in the text). The colored circles are locations of the continuous tide displacement measurements and the geophone locations (e2 and e6), as named in the legend. Blue and pink circles and dashed lines indicate locations of the ice flexture limit and slope break identified by Brunt and others (2010) using IceSat altimetry and the MOA, respectively. 


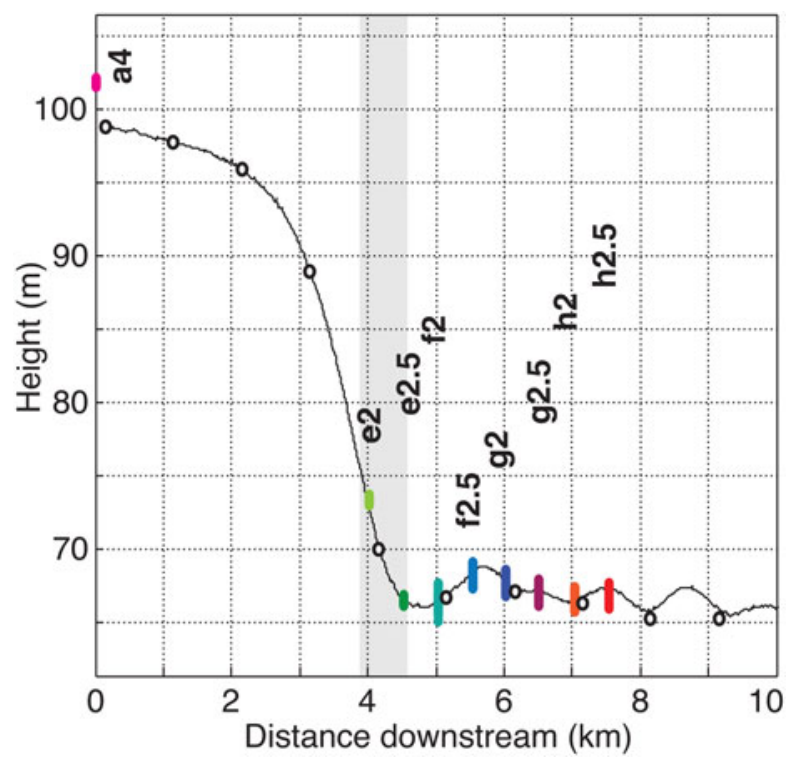

Fig. 4. Ranges of instantaneous GPS-derived vertical positions of the continuous GPS stations in the grid together with surface relief measured along the true left edge of the grid using real-time kinematic GPS. The range on station a4 demonstrates error in the instantaneous vertical positioning. The colors of the continuous marks match other figures and the open black circles include the locations of other marks in the strain grid. The circles and line do not match exactly because they are offset by $1 \mathrm{~km}$. The strand crack zone is indicated by gray shading.
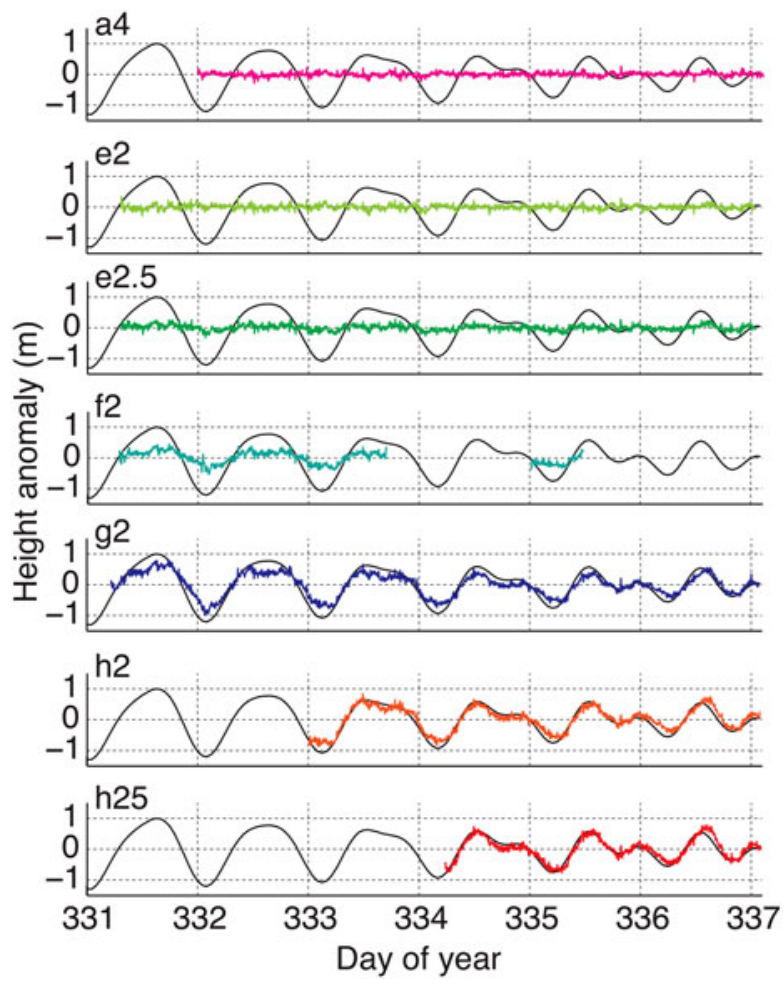

Fig. 5. Time series of height anomalies at tide stations (colored lines) together with tide prediction (black line, Personal communication, L. Padman).

undulations is not known but they do rise and fall together with the tide (Fig. 5) We also use the low-frequency radar profile to measure ice thickness along the edge of the strain
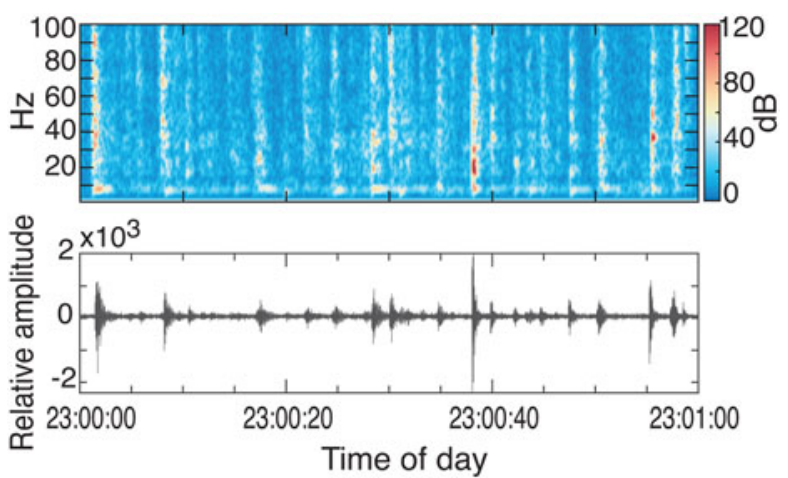

Fig. 6. Spectrogram and seismogram over a 1 min interval during a falling tide on 28 November 2007, near station e2. Spectrogram computed using the Matlab "spectrogram" function with a 120sample window and $95 \%$ overlap.

grid and this is shown together with other related quantities in a later figure.

\subsection{Seismicity}

Seismicity in the KIS grounding zone was observed between 27 November and 3 December of 2007 using three RefTek 130-01 recorders with GPS clocks. Two of the recorders operated over the complete interval. Data were collected continuously at a sampling rate of $250 \mathrm{~Hz}$. The typical event we heard while working in the area was a swarm of louder and quieter popping noises distributed over a few seconds. This several-second long swarm activity is expressed in the geophone record (Fig. 6). Swarms of microscale events are likely related to the same macroscale feature (Heeszel and others, 2014).

It is not possible to locate event epicenters with our data but we do associate the lower frequency part of the signal, between 5 and $15 \mathrm{~Hz}$, with cracking near the ice surface (Roux and others, 2010; Heeszel and others, 2014). Acoustic emission density is computed in the $5-15 \mathrm{~Hz}$ band by counting peaks above a threshold (10 times the background amplitude) in 10 min windows after applying a Hilbert transform to the time series (Fig. 7). The emission in this band is large during the the falling tide and negligible at other times. Emission density is largest when the rate of change in the tide height is largest.

\subsection{Ice motion}

Eight observation marks referred to here as 'tide stations' were established at $500 \mathrm{~m}$ intervals approximately in line with the ice flow direction to measure continuous displacement of the floating ice (Figs 3-5). Five geodetic-quality, Trimble 5700/R7 GPS antennas and receivers were used to record at least $2 \mathrm{~d}$ of data at each of the eight stations. The tide stations were located in a rectangular strain grid described next. A GPS base station that ran continuously during our work in the area provides a reference point $2 \mathrm{~km}$ upstream of the steepest part of the grounding zone slope and $4 \mathrm{~km}$ upstream of the tide stations. The Canadian Reference System Precise Point Positioning service (CSRS-PPP, software version 1.04 246) was used to establish absolute positions of the base station and tide stations. The $1 \sigma$ (standard deviation) of the vertical position of the (not floating) base station is $0.092 \mathrm{~m}$. This is similar to the standard deviation over shorter intervals for 

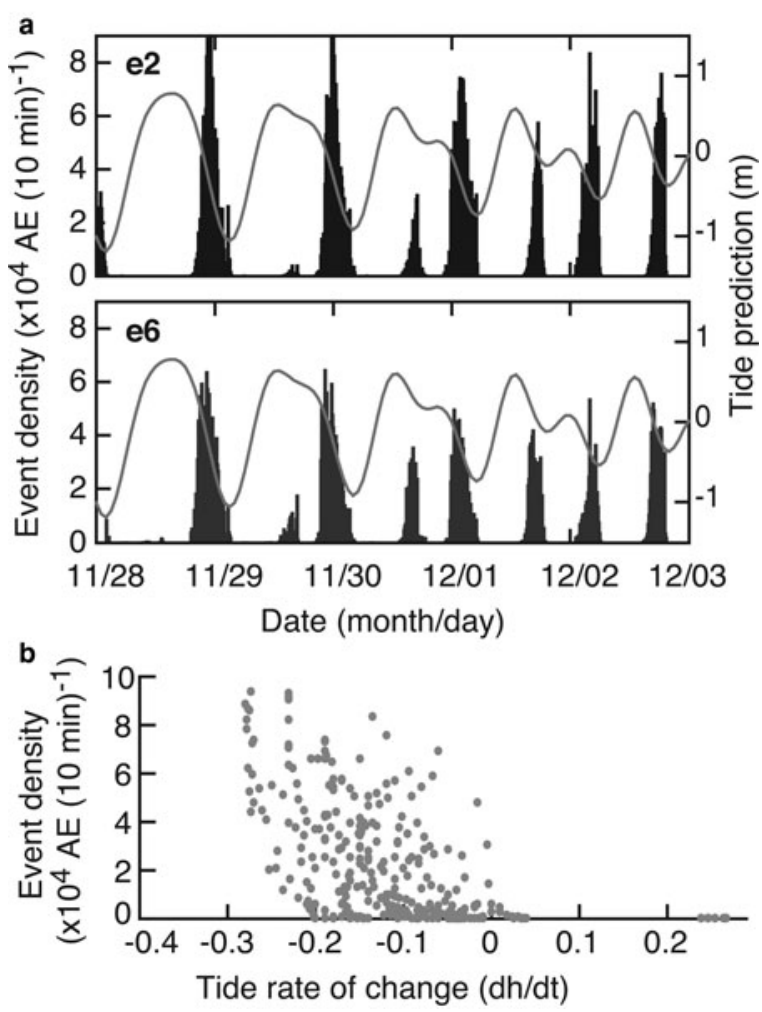

Fig. 7. Acoustic emissions and the tide. (a) Event density between 5 and $15 \mathrm{~Hz}$ near station e2 and near e6, at a point $4 \mathrm{~km}$ across-grid from e2, together with the tide prediction for this location (gray line, Personal communication, L. Padman). (b) The relationship between event density and rate of change in tide height at e2.

vertical positioning on the floating ice. Surface elevation along an edge of the grid was observed using real-time kinematic GPS via a sled-mounted antenna.

Floating ice is subject to an inverse barometer effect (IBE: Padman and others, 2003). The raw data shown in Figures 4, 5 are not modified to account for this effect but a correction is applied later, when the vertical positions are used with a beam bending model. We use Padman and other's estimated RIS rate of $-0.82 \mathrm{mhPa}^{-1}$ and pressure variations recorded at the nearby Siple Dome AWS and archived by the University of Wisconsin Automatic Weather Station Program http://amrc.ssec.wisc.edu/. The corrections on the 2007 tide station positions are in the range $\pm 0.12 \mathrm{~m}$, a value similar to the uncertainty in the GPS-derived positioning.

A $10 \mathrm{~km} \times 6 \mathrm{~km}$ rectangular grid of steel conduit poles planted vertically in the firn was installed across the grounding line transition in 2006. The grid spacing is $1 \mathrm{~km}$. The grid was surveyed in November 2006 and resurveyed in November 2007 using the Trimble 5700/R7 antennas and receivers and a rapid-static scheme. With two continuous base stations recording, individual GPS antennae and receivers were used to record $\sim 15$ min of data at each mark within the grid. Network adjustments made using the Trimble postprocessing software TGO $\vee 1.6$ were used to establish station locations within the grids. Ice speed ranges from $0.04 \mathrm{~m} \mathrm{a}^{-1}$ in the grounded ice to $7.37 \mathrm{~m} \mathrm{a}^{-1}$ where the ice is floating. For the KIS grid, the mean error on adjusted horizontal coordinates is $0.032 \mathrm{~m}$ in 2006 and $0.036 \mathrm{~m}$ in 2007, and the mean error in the adjusted vertical positions is $0.03 \mathrm{~m}$ in 2006 and $0.15 \mathrm{~m}$ in 2007. The larger adjustment error is similar to the scale of the IBE in that year. Errors on individual adjusted coordinates (reported by TGO) are used to propagate errors in subsequent calculations. These data were reported and used in a Masters thesis at Portland State University (Personal communication, F. Seifert, 2012) but have not been otherwise published.

Displacement rates of marks in the grid are used to compute horizontal velocities, from which finite strain rates $\dot{\epsilon}_{i j}$ associated with viscous deformation are computed as the gradients of those fields:

$$
\dot{\epsilon}_{i j}=\frac{1}{2}\left(\frac{\partial u_{i}}{\partial x_{j}}+\frac{\partial u_{j}}{\partial x_{i}}\right)
$$

in which $i, j$ are two orthogonal horizontal directions, $u$ represents velocity and $x$ represents position in a local coordinate system. The strain grid is oriented with its long axis approximately in the flow direction so the principal tensile stress is in the along-grid direction. We use mean acrossgrid strain rates and stresses in our models. Ice is speeding up and stretching in the downstream direction across the grounding zone, increasing from near zero to $\sim 7 \mathrm{ma}^{-1}$ over the $11 \mathrm{~km}$ length of the grid.

\section{ANALYSIS}

The ocean tide drives continuous change in the curvature (bending) of ice in the grounding zone. This, in turn, drives continuous change in the stress field within the ice and here is where we look to find the connection between tide height and episodic fracture propagation. The rising and falling tide clearly has other effects, for example, on WIS, where the falling tide increases loading on the bed and induces slip events in the ice plain (Winberry and others, 2009). Those loading-unloading events would produce paired compression and extension in the horizontal direction and seismic tremor (Winberry and others, 2013), not apparent in our data.

The hypothesis we put forward and test is simple: bending stresses associated with tidal bending either promote (falling tide) or suppress (rising tide) fracture propagation on the downstream portion of the grounding zone slope. The farfield resistive stresses are locally largest where the ice is fully afloat so bending must shift the site of largest vertical compression upstream of that location in order for our hypothesis to be correct. To conduct our test we use curvature variations from our observations, a bending model to infer Young's modulus, and a linear elastic fracture mechanics approach to compute stress intensity at the tip of a half-crack propagating vertically through the firn from the surface (Van der Veen, 1998; Scambos and others, 2000), without and with stresses due to bending.

\subsection{Time series}

Tide-induced vertical displacement of the ice is evaluated using the continuous GPS positioning (Fig. 5) and a tide prediction for the observation interval (Personal communication, L. Padman, 2012). Autocorrelations of individual tide station motion and correlations between the tide stations and the tide prediction are computed using the 'NEST' v.1.01 toolbox developed by Kira Rehfeld at the Potsdam Institute for Climate Impact Research: http://tocsy.pikpotsdam.de/nest.php. This toolbox implements an approach developed for irregular time series based on Gaussian-kernel 


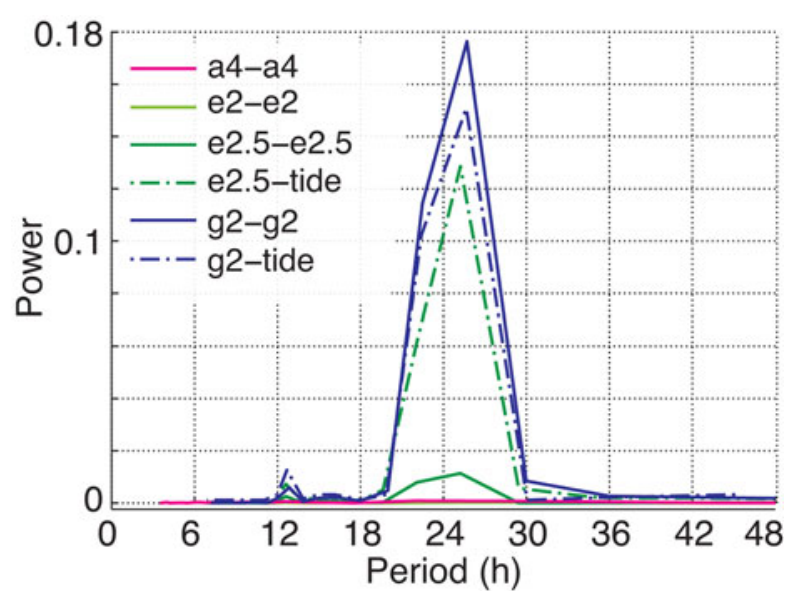

Fig. 8. Spectral power for autocorrelations and correlations with the tide prediction at various GPS time series. Station e2 is near the upstream limit of the strand cracks, e2.5 is at the slope break and g2 is $2 \mathrm{~km}$ downstream of e2 and the longest record in the dataset.

weighting functions (Rehfeld and others, 2011), avoiding interpolation of the relatively noisy GPS signals. Fourier transforms of the resulting similarity functions are used to identify dominant periods in the correlations.

Periodicity in the vertical motion is used to locate the upstream limit of flexure. Stations downstream of e2.5 produce strong autocorrelations at a period of $\sim 25 \mathrm{~h}$ and weaker peaks at a semi-diurnal period of $\sim 12.5 \mathrm{~h}$. The station in this group for which we have the longest record, g2, is shown in Figure 8. No tidal period is identified at e2, the station near the upstream limit of the strand crack zone, or at a4, the farthest upstream location. The vertical signal at station e2.5, near the slope break and the downstream limit of the strand cracks, is relatively weak but clearly due to the tide.

According to the vertical motion data, the flexure limit is close to station e2, and also to the upstream limit of the visible strand cracks. Note that the break in slope that may be used to identify the grounding line in images like the MODIS Mosaic of Antarctica (MOA: Scambos and others, 2007; Haran and others, 2014) is near station e2.5 in our GPS profile of the line. Brunt and others (2010) located the flexure limit and slope break close together and slightly downstream of the locations we identify, using 2003 ICESat tracks and MOA (Fig. 3).

\subsection{Bending}

Horizontal dimensions are large compared with vertical dimensions in the grounding zone and across-flow variation in ice thickness and flow are small relative to along-flow variation. Both elastic and viscoelastic models have been used by various authors to represent ice bending through the grounding zone, the preference depending in part on fit to observed ice displacement (Vaughan, 1995; Reeh and others, 2003). The timescales of interest here are short compared with the Maxwell time, so the linear elastic approach is suitable for our objectives. Different properties for the substrate beneath the floating and grounded ice may also be important (Walker and others, 2013). A soft sediment bed would extend the limit of flexure upstream and away from the slope break but our GPS observations do not indicate that this is the case.

With the above considerations in mind, we treat the study area as a beam supported from below with no vertical motion at a fixed grounding line end and vertical motion that matches the tide beyond the hinge zone. We follow the work of other authors in this regard (cf. Holdsworth, 1969; Johnson, 1970; Vaughan, 1995; Sergienko, 2013; Marsh and others, 2014). The bending model derives from balance between loadings $q$ and shear forces $Q$ at distances $x$ along the beam

$$
q=\frac{\mathrm{d} Q}{\mathrm{~d} x}
$$

and balanced moments $M$

$$
Q=\frac{\mathrm{d} M}{\mathrm{~d} x}
$$

When a moment $M$ is applied to an isotropic elastic beam, it bends into an arc.

The radius of curvature $r$ at any location $x$ along the beam is

$$
r=\frac{\left(1+(\mathrm{d} w / \mathrm{d} x)^{2}\right)^{3 / 2}}{\left|\mathrm{~d}^{2} w / \mathrm{d} x^{2}\right|}
$$

in which $w$ represents the displacement of the neutral axis. In the present case, relatively small slopes mean that $(\mathrm{d} w$ ) $d x)^{2}$ is $\ll 1$. The radius of curvature is related to strains, and in turn stresses, in the ice by considering deformations above and below the neutral axis (cf. see Chapter 2 of Johnson, 1970). For small angles of rotation and small changes in length $\mathrm{d} u / \mathrm{d} x$, the associated fiber strain $\epsilon_{\mathrm{f}}$ is

$$
\frac{\mathrm{d} u}{\mathrm{~d} x}=\epsilon_{\mathrm{f}}=\frac{y}{r}
$$

in which $y$ represents distance from the neutral axis. Assuming a linear elastic material means that normal stresses $\sigma$ and strains $\epsilon$ are proportional according to Young's modulus $E$ and Poisson's ratio $v$ as $\sigma_{x}=E \epsilon_{x,} \sigma_{y}=(E / v) \epsilon_{x \prime}$ and so on for other components.

The relationship between the radius of curvature and the fiber stresses $\sigma_{\mathrm{f}}$ is thus

$$
\epsilon_{\mathrm{f}}=\frac{\sigma_{\mathrm{f}}}{E}=\frac{y}{r} .
$$

Concave-up bending, for example, produces horizontal compression (vertical extension) above the plane and horizontal extension (vertical compression) below the plane. The strains are largest (and opposite in sign) at the upper and lower surfaces and go to zero along a neutral axis within the beam.

The force and momentum balances are used together with the curvature and the stress/strain relationship to derive analytical models of bending $w(x)$ for various boundary conditions (Johnson, 1970). For the ice shelf, a free floating condition $w=w_{0}(t)$ at $x=\infty$ represents a far field (unbent) tide forcing on the ice, a fixed condition $w=0$ and $\partial w / \partial x=0$ at $x=0$ for all times $t$ represents the grounding line, and the result is

$$
w(x)=w_{0}\left(1-e^{-\beta x}(\cos \beta x+\sin \beta x)\right)
$$

with

$$
\beta^{4}=\frac{\rho_{\text {sw }} g\left(1-v^{2}\right)}{4 E I}
$$




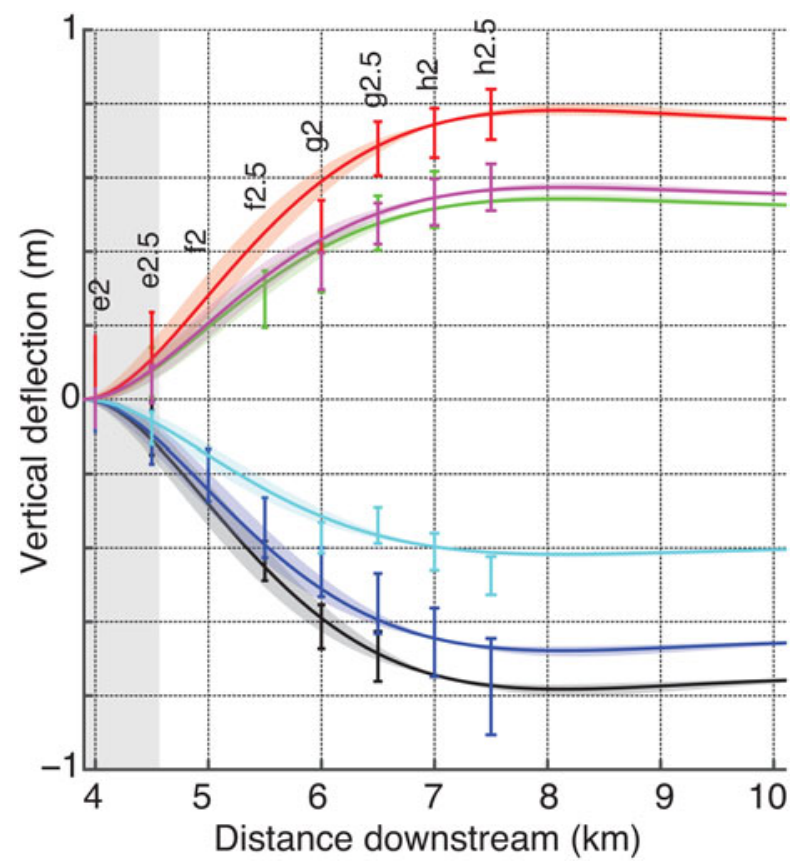

Fig. 9. Linear elastic bending with $E=0.045 \mathrm{GPa}, v=0.3$ for $w_{0}=$ 0.75 (red), 0.55 (purple), 0.52 (pink), -0.4 (light blue), -0.65 (dark blue), -0.75 (grey). The points and error bars show mean measured deflections and $1 \sigma$ standard deviations in $1 \mathrm{~h}$ windows around the three high and three low tides. An IBE correction is applied at g2.5, h2 and h2.5. Shaded areas encompass $\pm 30 \mathrm{~m}$ in the ice thickness. Distances downstream match other plots.

The collection of terms $\beta$ is in effect a damping parameter that translates the elastic beam theory to this particular setting. The constant $\rho_{\mathrm{sw}}$ represents the density of sea water, $g$ represents the acceleration due to gravity, and the moment I goes with the thickness $h$ as $I=(2 / 3) h^{3}$.

Elastic properties of the ice are estimated using the bending model. We do this in a forward way, calculating vertical deflections for several high and low tides during our 2007 observation period, IBE corrections on stations g2.5, h2 and $\mathrm{h} 2.5$, and a uniform ice thickness of $590 \mathrm{~m}$, derived from the radar profile (Fig. 9). We place the fixed point $100 \mathrm{~m}$ upstream of the tide station named e2. Our observations at a range of high and low tides are well represented with $E=$ $0.045 \mathrm{GPa}$ and $v=0.3$. The value for Young's modulus is an order of magnitude smaller than used elsewhere in similar contexts (cf. Vaughan, 1995). Such a value is required to generate the the relatively tight shape of the tidal perturbation in the hinge zone. Larger $E$ would reduce the curvature and spread the deformation over a much longer distance downstream than we observe. The ice thickness would need to be half its observed value to bring the bending back to its observed shape if we use an order of magnitude larger $E$. Cyclic loading may explain this outcome. The ice is advecting away from the grounding zone at $<10 \mathrm{~m} \mathrm{a}^{-1}$ and so the same ice bends repeatedly with the tide. Cyclic loading is associated with softening of other materials (e.g. Aguilar and others, 2001; Mao and others, 2006; Kunz and others, 2011) and may result in the apparent lower $E$ here.

With this information, we compute fiber stresses (Eqn (6)) that are required to test our hypothesis. It is important to note that the selection of bending model matters most for the estimated elastic modulus $E$. The perturbation to the beam shape caused by the tide comes from our time series observations.

\subsection{Fracture propagation}

Fractures are an observable effect of stress in a material. They initiate at flaws and propagate in the most compressive principal stress direction when stress intensity at a crack tip is large enough to overcome the fracture toughness of the material. Once initiated, propagation continues until the stress intensity at the propagating tip falls below the value required to overcome the fracture toughness. All other things being equal, the longer a fracture becomes, the more likely it is to continue propagating. In the case of vertical propagation, horizontal compression due to the overlying material increases with increasing fracture length and limits the ultimate depths of crevasses (cf. Van derVeen, 1998). In the present case, convex up bending, which produces horizontal extension and vertical compression above the neutral axis, may enhance vertical propagation of strand cracks, while convex down bending could suppress propagation.

Stress intensity in the present case depends on the magnitude of resistive stresses associated with viscous deformation of the ice, horizontal compression associated with the weight of the overlying firn, near field effects of the fracture itself and time-varying stresses associated with the tidal bending. Following Van derVeen (1998), the stress intensity $K_{l}$ for mode I opening in a dry fracture is the sum of the effect of resistive stress and the effect of the overburden, which tends to close the fracture. The first component is

$$
K_{I}^{(1)}=f(\lambda) \tau(\pi d)^{1 / 2}
$$

in which $f(\lambda)$ is an empirically derived function of the ratio of crevasse depth $d$ to ice thickness and $\tau$ is the deviatoric stress normal to the fracture plane. Where the ice is bending, fiber stresses normal to the fracture plane are included

$$
K_{l}^{(1)}=f(\lambda)\left(\tau+\sigma_{f}\right)(\pi d)^{1 / 2} .
$$

Both $\tau$ and $\sigma_{\mathrm{f}}$ depend on $x$. In the case of the fiber stresses, the dependence involves both location and time, yielding timechanges in the sign and location of largest $\sigma_{\mathrm{f}}$.

Resistive stresses are computed using the inverse form of the flow law:

$$
\tau=\bar{B} \epsilon_{1}^{1 / 3}
$$

in which $\bar{B}$ represents the temperature-dependent inverse rate factor (p. 16: Van derVeen, 1999) and $\epsilon_{\mid}$represents the strain rate orthogonal to the fracture trace. We use acrossgrid mean values of the extensive principal strain rate and a temperature of $-20^{\circ} \mathrm{C}$ for our calculation. Warmer ice will decrease the viscous stresses and thus reduce the stress intensity while colder ice will increase it. Along-flow stretching, and thus the stress normal to the fracture plane, rises as the ice goes afloat and then falls slightly (Fig. 10).

The overburden contribution to the stress intensity:

$$
K_{l}^{(2)}=\frac{2 \rho_{\mathrm{i}} g}{(\pi d)} \int_{0}^{d}\left[-b+\frac{\rho_{\mathrm{i}}-\rho_{\mathrm{s}}}{\rho_{\mathrm{i}} C}\left(1-e^{-C b}\right)\right] G(\gamma, \lambda) \mathrm{d} b
$$

in which $\rho_{\mathrm{i}}$ and $\rho_{\mathrm{s}}$ represent the ice and surface snow densities respectively, $b$ represents the vertical coordinate along the fracture, $C$ is a densification constant taken to be $0.02 \mathrm{~m}^{-1}$, and $G$ is a numerically-derived function of $\gamma=b / d$ and $\lambda$. We use $\rho_{\mathrm{s}}=450 \mathrm{~kg} \mathrm{~m}^{-3}$. 

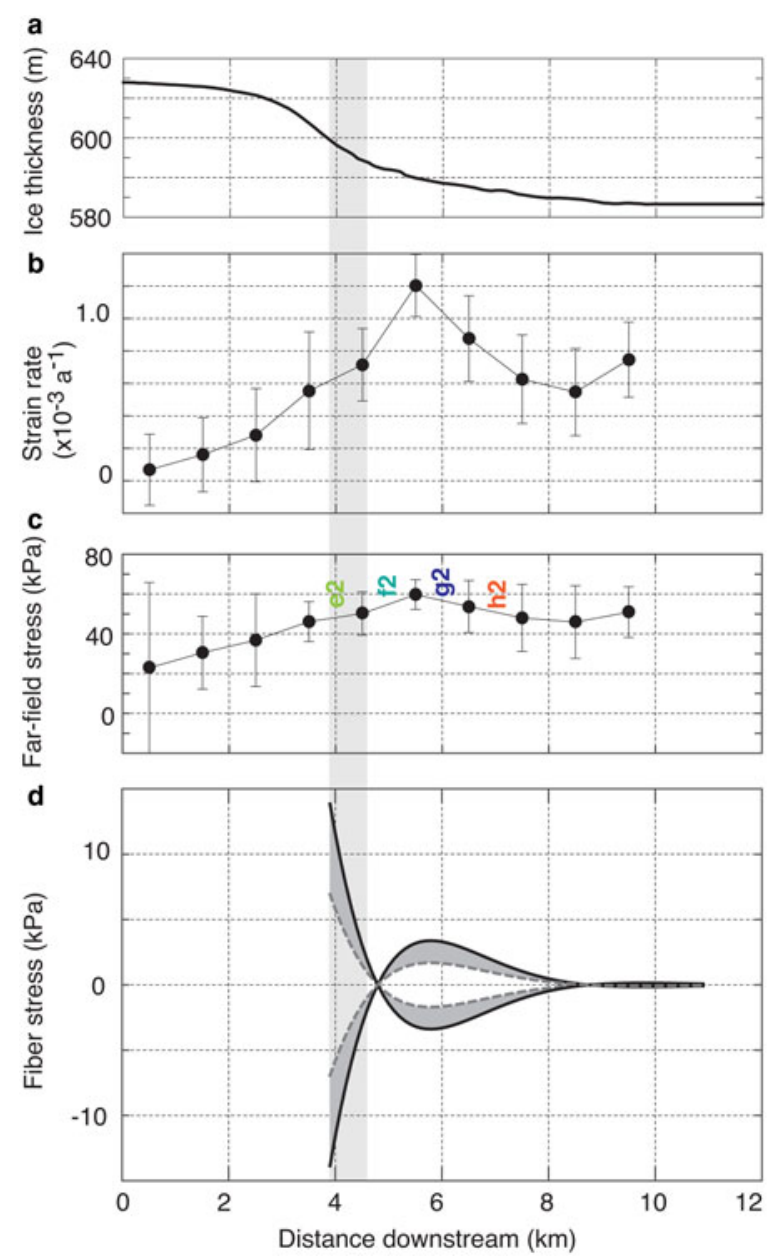

Fig. 10. Quantitative characterization of the KIS grounding line transition. (a) Ice thickness. A uniform thickness of $590 \mathrm{~m}$ is used in the bending calculation. (b) Along-flow strain rate from velocity gradients in the strain grid and (c) resulting far-field stresses, with the propagated error shown as a vertical bar. (d) Fiber stresses at the upper surface from the bending model; the black solid lines represent bending at $\pm 1 \mathrm{~m}$ and the grey dashed line indicates bending at $\pm 0.5 \mathrm{~m}$ tide. In this case, positive values indicate horizontal extension (and vertical compression). Fiber stresses range from maximum values at the upper surface to zero at the neutral plane. Note the difference in scales between panels (c) and (d). The gray vertical band indicates the strand crack zone.

\subsection{Synthesis}

We use far-field glaciological stresses derived from the measured strain rates and fiber stresses from the beam bending model to test our hypothesis that bending associated with the falling tide promotes fracture propagation, or conversely, that bending associated with the rising tide suppress propagation. We do this by computing stress intensity $K_{l}^{(1)}+K_{l}^{(2)}$ at the tips of single fractures of various depths $d$ and tide station locations for three cases, one without and two with fiber stresses from tide perturbations in the range, -0.5 to $-1 \mathrm{~m}$ and from +0.5 to $+1 \mathrm{~m}$ (Figs 10,11 ). Where the resulting stress intensity exceeds the fracture toughness of ice, $100-300 \mathrm{kPa} \mathrm{m}^{1 / 2}$ (Rist and others, 2002), propagation is likely. The lower end of that range is more appropriate for firn, while the higher end is more appropriate for dense glacier ice.

Vertical compression above the neutral axis increases on the falling tide near the fixed end of the domain, when the curvature is convex up close to the grounding line and concave up farther downstream. The opposite holds on the rising tide. This detail of the bending is important. As the tide falls (Fig. 11b), stress intensity sweeps higher at stations e2 and e2.5, increasing the likelihood of fracture propagation, while it experiences little change at $\mathrm{f} 2$ and sweeps slightly lower at stations f2.5 and g2. Stations e2 and e2.5 are both in the strand crack zone while the others are outside of it. The opposite occurs on the rising tide. Stress intensities in the strand crack zone sweep away from the fracture criterion while sites far downstream of the strand crack zone, f2.5 and g2, sweep toward it. The change in stress intensity is, in both cases, large for sites near the flexure limit boundary and small for sites away from it.

\section{DISCUSSION}

The calculations presented here support our hypothesis that tidal bending in the grounding zone tends to promote (suppress) fracture propagation on the falling (rising) tide. Even though they are locally large, resistive stress associated with the transition from grounded to floating are unlikely to generate many strand cracks (panel (a) in Fig. 11). Moreover, the largest stress intensities associated with viscous deformation are downstream from where we observe fractures in the field. This implies that some other process is required to generate the abundant strand cracks we observed. The tidal pacing of fracture propagation points toward tidal bending as that process. Bending associated with the falling tide generates horizontal extension (vertical compression) that, when added to the resistive stresses, increases stress intensity closer to the limit of flexure and moves the region where fractures may propagate closer to this boundary than would otherwise be the case. This shift agrees with our field observations. The situation reverses on the rising tide and fracture propagation becomes less likely in the zone where strand cracks are observed.

The effect we investigate is subtle. Fracture propagation is possible but should be relatively rare at the KIS grounding line because the resistive stresses in the ice are never very large. The effect of the tidal perturbation is to modify the likelihood of those rare events, and to shift up/downstream the region where propagation is most likely to occur. Cyclic fatigue of the ice, which we suggest leads to a relatively low Young's modulus, may also promote failure of the material, but the tidal pacing of the observed acoustic (crack propagation) events requires the fiber stresses arising from tidal bending to be a primary driver of the events.

Different selections for material properties would modify the outcome of our calculations, as could the application of a different bending model. If a larger value is adopted for Young's modulus, the damping parameter $\beta$ would be smaller, and together these parameters would generate longer wavelength bending, larger fiber stresses, larger stress intensities and a downstream expansion of the strand crack zone. Regardless of parameter values, the bending model maximizes fiber stresses at the point where we fix the grounding line. A model with a soft-sediment substrate upstream of the grounding line would extend the region of flexure upstream of the point of floatation and create additional bands of alternating-sign curvature upstream of that point. Neither of these alternatives is a better match to our observations and neither would change the underlying nature of the bending effect: the tendency to promote 

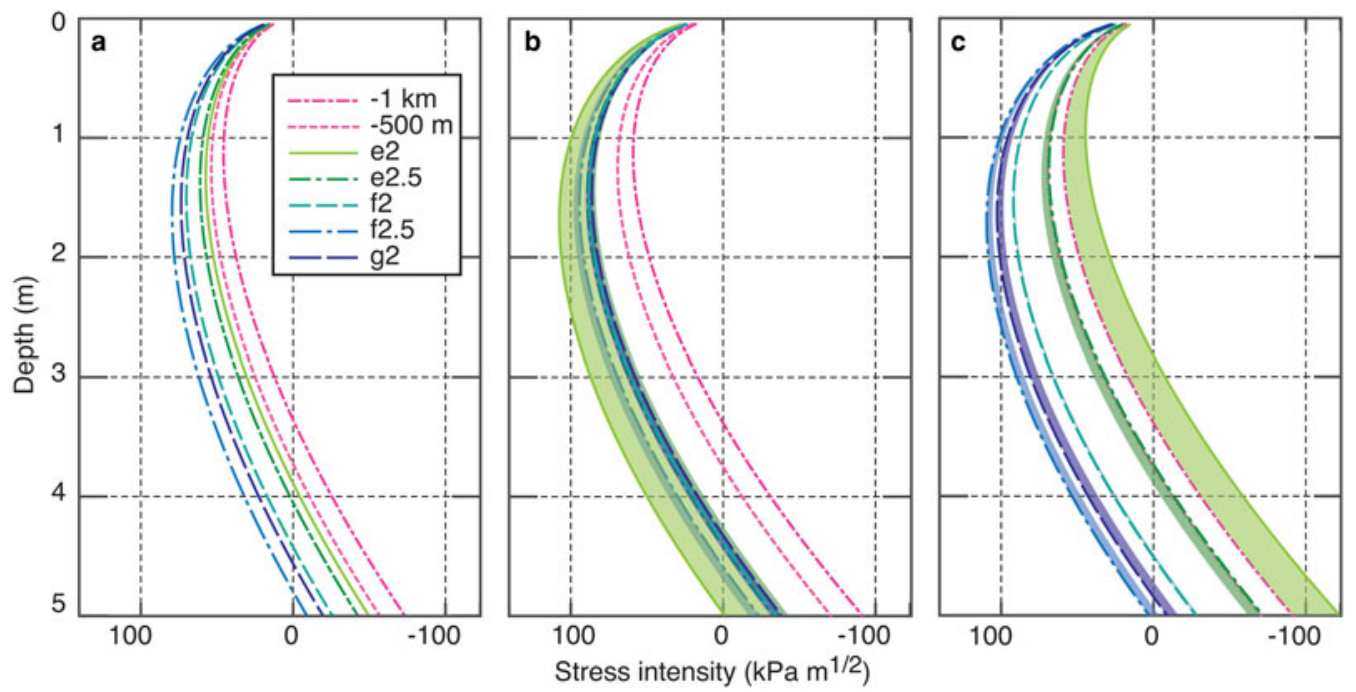

Fig. 11. Stress intensity factors for crack tip depths ranging from 0.1 to $5 \mathrm{~m}$, at $500 \mathrm{~m}$ intervals along flow. Stress intensity at each depth is computed for cases with (a) no tidal bending, (b) falling tide ranging from -0.5 to $-1 \mathrm{~m}$, and (c) rising tide ranging from +0.5 to $+1 \mathrm{~m}$. Colored shading spans this range and the heavy colored lines are on the +1 and $-1 \mathrm{~m}$ sides of the ranges, with the effect that the colored zones are sweeping through the falling (rising) tide. Presented this way, it is seen that e2 transitions toward increased likelihood of propagation on the falling tide while sites farther downstream transition away. The opposite occurs on the rising tide. The threshold for fracture propagation in firn is $\sim 100 \mathrm{kPa} \mathrm{m}^{1 / 2}$. Strand cracks are observed around and between e2 and e2.5.

strand crack formation on the falling tide and the tendency to suppress it on the rising tide.

Both the magnitude of the resistive stresses and cyclic loading by the tide may explain why strand cracks are abundant at the KIS grounding line while, in our observation, comparatively rare at the nearby WIS grounding line. At KIS, the grounded-to-floating transition is abrupt: from a no slip to free slip basal boundary condition. At WIS, the transition is more subtle as the ice goes afloat across a broad, lightly grounded 'ice plain' (Whillans and others, 2001). Like the strain rates, resistive stresses will be larger at a stuck/nostuck transition than at a more gradual one. The stuck/notstuck transition at KIS focuses deformation in a narrow zone.

\section{CONCLUSION}

Stresses arising from tidal bending in the ice shelf grounding zone modify resistive stresses in ways that can either promote or suppress fracture propagation. As ice flows across the grounded-to-floating transition, the change in the basal boundary condition causes locally large horizontal extension (vertical compression) but resistive stresses associated with that transition are unlikely to produce either the large number of fractures or the spatial distribution of fractures we observed in the KIS grounding zone. The tidal perturbation generates additional, time-varying fiber stresses, which modify that situation. In our model, strand crack formation is most favored close to the point of flotation on the falling tide because this is where and when the combination of resistive stresses and bending stresses generate the largest possible vertical compression (horizontal extension). Bending moves the site for active fracture propagation upstream from where resistive stresses alone might have the cracks appear. This result reconciles the locations of the observed fractures with measured strain rates (and calculated stresses). Further, in the somewhat special case of the KIS grounding zone, cyclic loading appears to be important to both the large number of strand cracks and the apparently low Young's modulus.

\section{ACKNOWLEDGEMENTS}

We thank Laurie Padman for the tide prediction and Harm Van Avendonk for the geophones of opportunity. We thank Doug MacAyeal for his council regarding the geophone data and two reviewers who asked important clarifying questions. The KIS and WIS strain grid data were used by Fiona Seifert in her MSc thesis, Origin of Surface Undulations at the Kamb Ice Stream Grounding Line, West Antarctica, at Portland State University. The field work was supported by NSF OPP grants ANT 05-38015 to Hulbe and ANT 0538120 to Catania. Support for data analysis was provided to Hulbe by the University of Otago. We appreciate the support of the University of Wisconsin Automatic Weather Station Program (NSF grants number ARC-0713843, ANT0944018, and/or ANT-1141908) where the atmospheric pressure data are archived.

\section{REFERENCES}

Aguilar MTP, Correa ECS, Monteiro WA, Ferreira NAM and Cetlin PR (2001) Work softening of drawn low carbon steel bars. Mater. Res., 4(2), 87-91 (doi: 10.1590/S1516-14392001000200008)

Anandakrishnan S and Alley R (1997) Tidal forcing of basal seismicity of ice stream C, West Antarctica, observed far inland. J. Geophys. Res., 102, 15183-15196 (doi: 10.1029/97JB01073)

Anandakrishnan S, Voigt DE, Alley RB and King M (2003) Ice stream D flow speed is strongly modulated by the tide beneath the Ross Ice Shelf. Geophys. Res. Lett., 30(7) (doi: 10.1029/2002GL016329)

Bindschadler RA, King MA, Alley RB, Anandakrishnan S and Padman L (2003) Tidally controlled stick-slip discharge of a West Antarctic ice streams. Science, 301, 1087-1089 (doi: 10.1126/science.108723)

Brunt K, Fricker H, Padman L, Scambos T and O'Neel S (2010) Mapping the grounding zone of the Ross Ice Shelf, Antarctica, using Icesat laser altimetry. Ann. Glaciol., 51(55), 71-79 (doi: 10.3189/172756410791392790)

Cruikshank K and Aydin A (1994) Role of fracture localization in arch formation, arches national park, Utah. Geol. Soc. Am. Bull., 106, 879-891 (doi: 10.1130/0016-7606(1994)106<0879: ROFLIA > 2.3.CO;2) 
Fretwell P and 59 others (2013) Bedmap2: improved ice bed, surface and thickness datasets for Antarctica. Cryosphere, 7, 375-393 (doi: 10.5194/tc-7-375-2013)

Haran T, Bohlander J, Scambos T, Painter T and Fahnestock M (2014) MODIS Mosaic of Antarctica 2008-2009 (MOA2009) Image Map. National Snow and Ice Data Center, USA, Electronic data (doi: 10.7265/N5KP8037)

Heeszel DS, Fricker HA, Bassis J, O'Neel S and Walter F (2014) Seismicity within a propagating ice shelf rift: the relationship between icequake locations and ice shelf structure. J. Geophys. Res.: Earth Surf., 119, 731-744 (doi: 10.1002/2013JF002849)

Hindmarsh RCA (1993) Qualitative dynamics of marine ice sheets. In Peltier WR ed. Ice in the climate system, NATO ASI Series I (12). Springer-Verlag, Berlin, 67-99 (doi: 10.1007/978-3-64285016-5_5)

Holdsworth G (1969) Flexure of a floating ice tongue. J. Glaciol., 8 (54), 385-397

Hulbe C and Catania G (2010) Ice-penetrating radar data across Siple Coast grounding lines, Version 1, NSIDC-0474. Technical Report. National Snow and Ice Data Center, Boulder, Colorado, USA (doi: 10.7265/N5M043BH)

Johnson AM (1970) Physical processes in geology. Freemand, Cooper, and Company, San Francisco, California, USA, iSBN 0-87735-319-0

Kunz L, Lukas P, Pantelejev L and Man O (2011) Stability of ultrafine-grained structure of copper under fatigue loading. Proc. Eng., 10, 201-206 (doi: 10.1016/j.proeng.2011.04.036)

MacGregor JA, Anandakrishnan S, Catania GA and Winebrenner DP (2011) The grounding zone of the Ross Ice Shelf, West Antarctica, from ice-penetrating radar. J. Glaciol., 57(205), 917-928 (doi: 10.3189/002214311798043780)

Mao S and 7 others (2006) Effect of cyclic loading on Apparent Young's Modulus and critical stress in nano-subgrained superelastic NiTi shape memory alloys. Mater. Trans., 47, 735-741 (doi: 10.2320/matertrans.47.735)

Marsh OJ, Rack W, Golledge NR, Lawson W and Floricioiu D (2014) Grounding-zone ice thickness from InSAR: inverse modelling of tidal elastic bending. J. Glaciol., 60(221), 526-536 (doi: 10.3189/ 2014JoG13J033)

Mercer JH (1978) West Antarctic ice sheet and CO2 greenhouse effect: a threat of disaster. Nature, 272, 321-325

Padman L, King M, Goring D, Corr H and Coleman R (2003) Ice shelf elevation changes due to atmospheric pressure variations. J. Glaciol., 49(167), 521-526 (doi: 10.3189/172756503781830386)

Reeh N, Christensen E, Mayer C and Olesen O (2003) Tidal bending of glaciers: a linear viscoelastic approach. Ann. Glaciol., 37, 8389 (doi: 10.3189/172756403781815663)

Rehfeld K, Marwan N, Heitzig J and Kurths J (2011) Comparison of correlation analysis techniques for irregularly sampled time series. Nonlin. Proc. Geophys., 18, 389-404 (doi: 10.5194/ npg-18-389-2011)

Retzlaff R and Bentley CR (1993) Timing of stagnation of Ice Stream C, West Antarctica from short-pulse radar studies of buried surface crevasses. J. Glaciol., 39(133), 553-561

Rist M, Sammonds P, Oereter H and Doake C (2002) Fracture of Antarctic shelf ice. J. Geophys. Res., 107(B1) (doi: 10.1029/ 2000JB000058)
Robin G (1958) Glaciology III. Seismic shooting and related investigations, volume 5 of Norwegian-British-Sweedish Antarctic Expedition 1949-52. Scientific results. Norsk Polarinstitut, Oslo, Norway

Roux P, Walter F, Riesen P, Sugiyama S and Funk M (2010) Observation of surface seismic activity changes of an alpine glacier during a glacier-dammed lake outburst. J. Geophys. Res., 115(F03014) (doi: 10.1029/2009JF001535)

Scambos T, Haran TM, Fahnestock MA, Painter TH and Bohlander J (2007) MODIS-based Mosaic of Antarctica (MOA) data sets: continent-wide surface morphology and snow grain size. Remote Sens. Environ., 111(2-3), (doi: 10.1016/j.rse.2006.12.020)

Scambos TA, Hulbe C, Fahnestock M and Bohlander J (2000) The link between climate warming and break-up of ice shelves in the Antarctic Peninsula. J. Glaciol., 47(154), 516-530 (doi: 10.3189/172756500781833043)

Schoof C (2007) Ice sheet grounding line dynamics: steady states, stability, and hysteresis. J. Geophys. Res., 112 (doi: 10.1029/ 2006JF000664)

Schoof C and Hewitt I (2013) Ice-sheet dynamics. Annu. Rev. Fluid Mech., 45, 217-239 (doi: 10.1146/annurev-fluid-011212140632)

Sergienko O (2013) Normal modes of a coupled ice-shelf/sub-iceshelf cavity system. J. Glaciol., 29(213), 76-80 (doi: 10.3189/ 2013JoG12J096)

Swithinbank C (1955) Ice shelves. Geogr. J., 121(1), 64-76 (doi: $10.2307 / 1791807)$

Thomas R, Sanderson T and Rose K (1979) Effect of climatic warming on the West Antarctic ice sheet. Nature, 277, 355358 (doi: 10.1038/277355a0)

Van der Veen C (1998) Fracture mechanics approach to penetration of surface crevasses on glaciers. Cold Reg. Sci. Technol., 27, 3147 (doi: 10.1016/S0165-232X(97)00022-0)

Van der Veen CJ (1999) Fundamentals of glacier dynamics. A. A. Balkema, Rotterdam, iSBN 90-5410-471-6

Vaughan D (1995) Tidal flexture at ice shelf margins. J. Geophys. Res., 100, 6213-6224 (doi: 10.1029/94JB02467)

Walker RT and 5 others (2013) Ice-shelf tidal flexure and subglacial pressure variations. Earth Planet. Sci. Lett., 361, 422-428 (doi: 10.1016/j.epsl.2012.11.008)

Whillans IM, Bentley CR and Van der Veen CJ (2001) Ice Streams B and C. In Alley RB and Bindschadler RA eds. The West Antarctic Ice Sheet: behavior and environment, volume 77 of Antarct. Res. Ser. AGU, Washington, DC, 257-281 (doi: 10.1029/ AR077p0257)

Winberry J, Anandakrishnan S, Wiens DA and Alley RB (2013) Nucleation and seismic tremor associated with the glacial earthquakes of Whillans Ice Stream, Antarctica. Geophys. Res. Lett., 40(2), 312-315 (doi: 10.1002/grl.50130)

Winberry JP, Anandakrishnan S, Alley RB, Bindschadler RA and King MA (2009) Basal mechanics of ice streams: insights from the stick-slip motion of Whillans Ice Stream, West Antarctica. J. Geophys. Res., 114, F01016 (doi: 10.1029/2008JF001035)

Winberry JP, Anandakrishnan S, Wiens D, Alley R and Christianson K (2011) Dynamics of stick-slip motion, Whillans Ice Stream, Antarctica. Earth Planet. Sci. Lett., 305(3-4), 283289 (doi: 10.1016/j.epsl.2011.02.052) 